\title{
Appraisal of Availability and Accessibility to Mortgage Finance for Sustainable Housing Delivery in Nigeria
}

\author{
Atamewan, Eugene Ehimatie \\ Eyo, Eyo-Ita Effiom \\ Effanga, Maureen Effanga
}

Department of Architecture,

Cross River University of Technology, Calabar, Nigeria.

Doi: 10.19044/esj.2017.v13n31p342 URL:http://dx.doi.org/10.19044/esj.2017.v13n31p342

\begin{abstract}
The success of any sustainable housing delivery system depends on a wide range of factors which includes availability and accessibility to mortgage finance. The paper appraised the availability and accessibility to mortgage finance towards sustainable housing delivery system in Nigeria. Methodology of study involved the use of questionnaires to collect information from respondents. Questionnaires were distributed to 320 staff of Cross River University of Technology, Calabar from a population of 1042 staff representing $30.7 \%$.. In addition, fifteen respondents purposely selected were orally interviewed. The data collected were analyzed using simple statistics, percentages and content analysis respectively. The secondary data involved available research data, official documents and data obtained from literature, books and journals. Findings reveal that the key challenge of accessing housing finance in Nigeria is affordability challenge. These include $10 \%-30 \%$ equity contribution, maximum tenures of only 10-25 years, high interest rate of $22 \%$ and the non-availability of long-term funding for housing development The paper opined that availability and accessibility to adequate mortgage financing will stimulate sustainable housing delivery process in Nigeria. Finally, strategies for promoting accessibility to housing financing for sustainable housing delivery is suggested in this paper.
\end{abstract}

Keywords: Calabar, financing, housing delivery, mortgage, sustainable development

\section{Introduction}

According to the UN Habitat (1984), financing is the process of obtaining funds or capital generally for the purpose of supporting a 
development and/or investment by gaining control over assets. Housing finance system is defined as a superstructure of laws, institutions and relationships between institutional and non-institutional units that facilitate the process of financial intermediation and capital formation in the Housing sector. Currently in Nigeria, housing is financed by a number of institutional sources which includes formal institutions namely budgetary appropriations, insurance companies; commercial and merchant banks State housing Corporations and the Federal Mortgage Bank. Also, informal institutions such as credit societies, money lenders have been financing housing construction (Adedeji \& Olotuah, 2012).

Sustainable development on the other hand has been defined by several authors but the meaning remain the same irrespective of the circumstances under which the concept is used. According to the National Affordable Housing Agency (NAHA) of Britain, sustainable development is described as a means of ensuring a better life for all categories of people both young and old, for present and future generations (NAHA, 2006). However, in terms of housing delivery systems, Jiboye (2011) defines sustainability as the development that is all inclusive in terms of social, economic and environment through the provision of adequate social services including housing, functional and livable environment for both the present and future occupant of the environment. Several housing delivery policies by the Nigerian government have failed to yield the desired result hence the housing deficit in Nigeria is put at over 17millions. Previous report has shown that over eighty-five percent of the urban population lives in rented accommodation and spend close to 50\% of their income on rents. Of these rented apartments, more than $90 \%$ are privately owned which is mainly due to inadequate mortgage financing (Fin-Mark Trust, 2010).

It should be noted that the operation of an efficient housing finance system in any economy is one of the strategies adopted by Government to stimulate the increased construction and delivery of available housing stock in order to reduce homelessness and create job opportunities for wealth generation among others. Unfortunately, in Nigeria the formal sector only constitutes about $15 \%$ of the housing market which is grossly inadequate to meet the ever increasing housing demands and where there are supplies, it is usually targeted at the medium and high income groups (Olotuah, 2015)

\section{Literature Review \\ Housing Finance}

It is no longer strange to know that some Nigerians especially the low-income groups living in the cities are homeless. The reason is that the cost of constructing or renting an accommodation is simply beyond the reach of an average Nigerians. Thus, the Nigerian housing sector challenge is that 
of affordability. Several housing construction and delivery system is targeted mainly at the middle and high income group of the population that can either pay cash or access mortgage finance from the banks. Housing financing is done through mortgages which in Nigeria is the primary responsibility of the Federal Mortgage Bank of Nigeria (FMBN). But the provisions of these mortgages to the income earners are through the National Housing Trust Fund (NHTF). However, only very few proportion of the income earners have been able to access these mortgages. This is because the performance of the housing finance system in loan disbursement has been dismal and discouraging.

The primary Mortgage Institutions are unable to render a good measure of financial mediation in housing delivery due to inherent challenges such as inadequate capitalization, weak management practices and inability to generate mortgages to qualify for the National Housing Trust Fund (Olotuah, 2015). Also, the absence of clear property and security rights, mandatory Governors consent, high interest rates as well as inadequate source of long-term funding are other factors that inhibit mortgage lending (Fin-Mark Trust, 2010). This is why the high income earners simply purchase their houses out rightly or via mortgage while some few low-income and medium income earners acquire their lands through savings and build their houses incrementally over a period of some years. Thus, there is an indication of declining activities in the housing finance in Nigeria (Fin-Mark Trust, 2010).

The large population of the homeless group in Nigeria, which cut across the low and medium income groups however suggest that housing developers and financial who are innovative have a potential growth opportunity in that sector of the economy.

\section{Access to Housing Finance in Nigeria}

Evidently, there is a drop in the low-income housing activity in Nigeria by most housing developers due to lack of capacity and expertise to develop housing products for the over populated low-income group in Nigeria housing market. Survey (FGN, 2016) has shown that access to housing finance is still very limited to a few individual who falls within the medium-income group which indicates that there is lack of access to housing finance. This problem has resulted in shortages of housing stock and increase substandard housing and homelessness among the poor populace in Nigeria.

An income class pyramid showing the income levels and their access to housing finance developed from a study by Fin-Mark Trust (2010) revealed that only about $30 \%$ in the upper and lower medium income group can access housing finance while a large portion of the population, the low- 
income group cannot access housing finance and would therefore require social housing.

Often times, most housing developers in the formal sector lack access to housing finance which adversely affect the supply and delivery of houses, hence they are left with the option of sourcing funds from deposit money banks with very high interest rates and other stringent conditions attached. Accordingly, the bulk of low-income individual home builders are compelled to source for housing finance from a more convenient and accessible classified as micro-credit organizations sources such as family, friends, "esusu" (traditional thrift societies), age/trade groups and traditional money lenders. The disadvantages of these sources of housing finance are that they are unsecured and very limited in their capital base (Nubi, 2006).

\section{Challenges to Accessing Housing Finance in Nigeria.}

The establishment of the National Housing Fund (NHF) in 1992 was aimed at solving the problems of mobilization of long-term funds for housing construction and delivery as well as maintains a stable base for affordable housing finance for the purpose of building construction, purchasing and improving of houses. However, the NHF since established has been bedeviled with the major challenge of inadequate capitalization due its failure to attract and pull resources from the informal private sector made up of self-employed workers, the formal private sector (commercial banks and insurance companies) and the ineffectiveness in the operations and capability of the Primary Mortgage Institutions (Olotuah \& Taiwo, 2013).

The major challenge of housing finance system in Nigeria is affordability. The affordability constraint intrinsic in the mortgage instrument limits access by the low-income population. These limitations include 20\%-30\% equity contribution, maximum tenures of only 10-15 years, high interest rate of $22 \%$. Other challenges are macro-economic mainly high inflation; policy and regulatory (Land Use Act, Property Registration, Taxes, Stamp Duties); unavailability of secondary market other than the PMIs; lack of credit enhancement vehicles (insurance); inadequate skilled manpower in the mortgage market; high cost of building materials cum over dependence on foreign materials and inadequate infrastructure development( Fin-Mark Trust , 2010).

According to Adedeji \& Olotuah (2012), for housing finance to be successful in sustainable housing delivery system, there must be a guaranteed continuous flow of funds. The authors opined in their study that the percentage of total beneficiaries of the NHF is infinitesimally small compared to the number of contributors which confirm the accessibility challenge to housing finance in Nigeria using the NHF Scheme as a yardstick. In their studies, (Chionuma, 2000; Bichi, 2002 and Fortune-Ebie, 
2004) agreed that the NHF is faced with a lot of operational challenges which includes non disbursement of NHF application loans due to non fulfilment of some stringent conditions, non submission of acceptable security of existing mortgages by PMIs, delays in perfection of fund mortgages and inability of PMJs to fund $20 \%$ of loans as one of the statutory requirements.

\section{Methodology}

Methodology of study involved the use of questionnaires to collect information from respondents. Questionnaires were distributed to 320 staff of Cross River University of Technology (CRUTECH), Calabar from a population of 1042 staff. The respondents comprised of academic staff, nonacademic, senior staff and technologists. The information contained in the questionnaire were centred on type of accommodation, ownership status, how acquired (source of funds), access to loans, challenges to housing loans, building land ownership, housing construction levels, Secondary sources of data was through systematic review of literature which include journal articles, conference materials, official documents and books. From the 320 questionnaires distributed, 265 were retrieved representing $82.8 \%$ for analysis. In addition, fifteen respondents purposely selected from those who returned their questionnaire were orally interviewed. The interview questions centred on contributions to NHF and access to houses and mortgage from the Federal Mortgage Bank of Nigeria (FMBN). The respondents cut across the four categories of employees in the University. Content analysis was used to analyse the results qualitatively which also helped to clarify some of the issues contained in the questionnaire.

\section{Results and Discussions}

\section{Number of Years in Employment of Respondents}

The respondents' number of years in employment (Table 1) shows that all the respondents have been in the University as employee foe between five and thirty years which by implication should guarantee them access to which ever source of funding available in Nigeria. This is because it takes a maximum of two years to get confirmation as a full staff of the University.

Table 1: Number of Years in Employment of Respondents

\begin{tabular}{cccccc}
\hline Years & $5-9$ & $10-15$ & $16-20$ & $21-25$ & Above 30 \\
\hline Frequency & 22 & 105 & 73 & 53 & 12 \\
Percentage & 8.3 & 39.6 & 27,6 & 20 & 4.5 \\
\hline
\end{tabular}

Authors' field survey, 2017 


\section{Monthly Income of Respondents}

The monthly income range of respondents shown in Table 2 reveals that respondents earns between fifty thousand naira $(\# 50,000)$ and three hundred thousand naira $(\# 300,000)$. This implies that the respondents fall within the middle income and high income groups in the society.

Table 2: Monthly Income of Respondents

\begin{tabular}{ccccccc}
\hline $\begin{array}{c}\text { Income in } \\
\text { Naira(Thousand) }\end{array}$ & $50-100$ & $101-150$ & $151-200$ & $201-250$ & $251-300$ & 300 \\
\hline Frequency & 35 & 63 & 85 & 57 & 25 & - \\
Percentage & 13.2 & 23,8 & 32.1 & 21.5 & 9.4 & - \\
\hline
\end{tabular}

Authors' field survey, 2017

\section{Respondents Housing Occupancy/Ownership Status}

From the sampled respondents (Table 3), 118 staff representing $44.5 \%$ resides in rented apartments while 92 representing $34.7 \%$ resides in the University Staff quarters. Also, 43 respondents (16.3\%) lives in their personal houses while only 12 staff $(4.5 \%)$ reside in family houses. This implies that about $83.7 \%$ of the respondents do not have houses of their own.

Table 3: Housing Occupancy/ Ownership Status

\begin{tabular}{ccccc}
\hline Type & Rented & $\begin{array}{c}\text { Personal } \\
\text { House }\end{array}$ & $\begin{array}{c}\text { Staff } \\
\text { Quarters }\end{array}$ & Family \\
\hline Frequency & 118 & 43 & 92 & 12 \\
Percentage & 44.5 & 16.3 & 34.7 & 4.5 \\
\hline
\end{tabular}

Authors' field survey, 2017

\section{Source of Fund for Housing}

All sampled respondents agree that they either own a house or are in the process of owning one. Hence, the sources of their housing funds vary. About two-third of the respondents (63\%) sourced funds from commercial banks (Table 4) while15.1\% from personal savings. Also, 18.1\% got houses directly from State government housing scheme while the remaining 3.8\% sourced funds elsewhere. However, records made available to the researchers by the University authority reveal that 56 staff are current beneficiary of the state government housing scheme for workers in Cross River State with their repayment period of ten years and monies deducted at sources monthly from their salaries.

Table 4: Source of Housing Funds

\begin{tabular}{ccccc}
\hline Source & Personal saving & Bank Loan & $\begin{array}{c}\text { State Govt. } \\
\text { Housing Scheme }\end{array}$ & Others \\
\hline Frequency & 40 & 167 & 48 & 10 \\
Percentage & 15.1 & 63 & 18.1 & 3.8 \\
\hline
\end{tabular}

Authors' field survey, 2017 


\section{Application for Loans from Banks for Housing}

From the respondents sampled, 177 of the 265 applied for one form of housing loan or the other from different banks and sources. This excludes 40 respondents with personal savings and 48 respondents on state government housing scheme. A total of 106 respondents representing 59.8\% had their applications sent to commercial banks being the highest (Table 5). This is followed by cooperative with 27 respondents (15.3\%), micro finance with 25 respondents (14.1) and 19 respondents (10.7) from other sources. This implies that in spite of the high interest rate charged by these banks which range from 20 to $25 \%$, apart from cooperatives, respondents had no other choice than resort to getting loans from these sources.

Table 5: Application for Loans from Banks for Housing

\begin{tabular}{ccccc}
\hline Bank & $\begin{array}{c}\text { Commercial } \\
\text { Bank }\end{array}$ & Cooperative & Micro finance & Others \\
\hline Frequency & 106 & 27 & 25 & 19 \\
Percentage & 59.8 & 15.3 & 14.1 & 10.7 \\
\hline
\end{tabular}

Authors' field survey, 2017

\section{Loan Utilization on Housing Project}

On the utilization of loans obtained by respondents, the results showed that the greater number of respondents (37.3\%) have only purchased land for building. This is followed by respondents who have completed their houses (24.8\%), while about $15 \%$ have their buildings nearing (80\%) completion. The proportion of respondents with uncompleted houses (Table 6) is $22.9 \%$. The implication here is that over $60 \%$ of respondents are not close to completing their houses.

Table 6: Loan Utilization on Housing

\begin{tabular}{ccccc}
\hline Stage & Completed & $\begin{array}{c}\text { Nearly (80\%) } \\
\text { completed }\end{array}$ & Uncompleted & $\begin{array}{c}\text { Purchase of } \\
\text { land }\end{array}$ \\
\hline Frequency & 38 & 23 & 35 & 57 \\
Percentage & 24.8 & 15 & 22.9 & 37.3 \\
\hline
\end{tabular}

Authors' field survey, 2017

\section{Access to Mortgage (Federal Mortgage Bank of Nigeria)}

All respondents interviewed agreed that they are all contributors to the National Housing Fund (NHF) since their first month of employment. It was gathered that over $90 \%$ of the respondents had at various times approached the FMBN for mortgage and houses based on the reasons for being a contributor to NHF. The negative response and refusal of the request was based on some reasons which are summarized as follows.

Land acquisition and documentation: The respondents said they were asked to produce proper land documentation and certificate of occupancy (CO) which has proven to be very unreachable as it is only issued 
by State governors. This requirement has hindered many applicants from accessing the fund.

Drawings and cost estimates: Respondents as applicant were also expected to submit dully completed and endorsed drawings comprising of architectural, mechanical, electrical and structural drawings by qualified professionals including bill of quantity for the cost estimates prepared and signed by a qualified quantity surveyor. It should be noted that the first two conditions are for applicants who choose to construct their buildings. But for outright purchase of houses constructed by registered developers (estates), these are not required as the houses already has the required documentation.

Equity contribution: Respondents as applicants must be able to pay upfront at least $10 \%$ of the total cost of their choice houses for houses not more than 5million naira, 20\% for houses between 5-10million naira and $30 \%$ for houses above 10 million naira. The respondents submitted that houses sold by developers are far beyond their reach which imposes the equity contribution of between $20-30 \%$ mandatory for them which is difficult to meet based on current economic realities.

Unavailability of houses by developers. Respondents submitted that their chances of being selected for approval were hampered unavailability of constructed houses for sale by developers. Unfortunately, there are no houses by developers ready for outright purchase. Only 56 staff of the university benefitted from the houses developed by the State government over eight years ago.

Repayment period: The maximum tenures of only 10-15 years repayment period automatically disqualify many respondents who have spent up to 20years in employment or more than 50 years old. This is because 35 years in employment is maximum for retirement.

Non-remittance of NHF contributions by employers: Respondents expressed shock and disappointment when they learnt their monthly NHF contributions have not been remitted to the NHF by their employers since 2015. This has automatically disqualified all applicants from the institutions since the last two years.

\section{Implications of Findings and Recommendations}

The inability of the NHF to live up to its aim of making houses available to the Nigerian workforce is not without its attendant problems. This is evidenced in the high proportion of workers within the middle and high income groups not been able to own houses. If these groups of income earners struggle to be accommodated in standard apartments in terms of rent or build their houses, one wonders what the fate of the no and low-income groups would be who constitutes the greater proportion of the Nigerian 
populace. This is worrisome and pathetic as most workers are forced to live in substandard housing and unhealthy environments.

The Nigerian housing sector is plagued with a lot of challenges as enumerated above among which are limited access to housing finance, due to unrealistic conditions for obtaining NHF loans. Therefore, urgent intervention is needed to ensure sustainability of housing for the teeming populace living in substandard houses or homeless.

Therefore, this paper puts forward the following recommendations which it believes if implemented will enhance sustainable and affordable housing delivery system in Nigeria. These recommendations are:

1. There should be establishment of housing microfinance, similar to what obtains in other developing and developed nations to provide both short and long term to low and medium income groups for housing development.

2. The requirements for land titling, registration and acquisition of certificate of occupancy $(\mathrm{CO})$ should be reviewed to allow for flexibility.

3. Existing mortgage institutions should be restructured and recapitalized to provide better funding and offer long-term funding for developers and would be house owners at relatively low (single digit) interest rate.

4. Accessibility of Nigerians to housing finance should be enhanced and guaranteed by relaxing the conditions attached for getting the housing funds through the NHTF. Especially for contributors. Government should ensure that the FMBN is strengthened financially to be more responsive in financing housing development.

5. The NHF deductions that have accrued over the years could be ploughed into construction of mass housing for the Nigerian workforce. Furthermore, NHF deductions should be stopped and made optional for workers if contributors' access to housing loans cannot be guaranteed.

\section{Conclusion}

Sustainable housing delivery is a function of the level of availability and accessibility to housing finance. Housing finance is pivotal to sustainable housing delivery. For sustainable housing delivery to be a reality in Nigeria, strategic investment in housing infrastructure and housing finance is non-negotiable and must be fully encouraged by government, as it is the foundation for economic growth and improved standard of living of populace. The study has shown that most respondents lack access to the housing fund. The NHF which would have been the easy access to housing fund for contributors as workers has stringent and unattainable requirements. Other sources of funds for housing development has high interest rate attached which has adversely affected housing ownership among Nigerian workers. However, despite the inability of FMBN through the NHF to meet 
the housing finance need of most Nigerians, especially workforce, they have still been able to have one form of shelter or another in some form through micro financing scheme and cooperatives. The Nigerian housing deficit put at over 17 million cannot be adequately tackled without availability and accessibility to housing funds.

\section{References:}

1. Adedeji, Y. M. D, Olotuah A. O. (2012), An Evaluation of Accessibility of Low-Income earners to Housing Finance in Nigeria. American-Eurasian Journal of Scientific Research. 7 (1), 23-31

2. Bichi, K.M.( 2002). Housing the Nigerian Population: Problems and Prospects. Journal of the Federal Mortgage Bank of Nigeria, 1(5), 30-31.

3. Chionuma, O.M. (2000). The role of Primary Mortgage Institutions in the Provision of Housing in Nigeria A paper presented at a National Workshop on Finance and Procurement of Housing and Infrastructure organized by the Institute of Quantity Surveyors on April 12, 2000).

4. Federal Government of Nigeria, FGN (2016). National Bureau of Statistics. A publication of the National Bureau of Statistics, 2016, Abuja.

5. Fin-Mark Trust (2010). Overview of the Housing Finance Sector in Nigeria. UK DFID; Bill and Melinda Gates Foundation 12(1), 1-52

6. Fortune-Ebie, S.P.O. (2004). National Housing Fund and the Housing Policy of the Federal Government as it affect the strength (weaknesses) Opportunity (threat) of the Nigerian Workers (A paper presented at a two-day Kaduna State Economic Summit organized by Kaduna Forum at Arewa House, Kaduna).

7. Jiboye, A. D. (2011). Ensuring Sustainable Development through an Effective Housing Delivery Process in Nigeria. African Journal of Social Sciences. 1 (2), 36- 45.

8. National Affordable Housing Association (NAHA. 2006. Sustainability; Policy Areas. [Online] Available: http;//www.housingcorp. gov. uk. Accessed December 27, 2016).

9. Nubi, T.O. (2006). Financing Urban Housing. Paper delivered in a workshop organized

10. by Nigeria Building and Road Research Institute (NBBRI) Abuja, Nigeria

11. Olotuah, A. O. (2015). Accessibility of Low-income Earners to Public Housing in Ado-Ekiti, Nigeria. Journal of Civil and Engineering Research. 7(7), 1-5 
12. Olotuah, A. O. and Taiwo, A. A. (2013). Housing the Urban Poor in Nigeria through Low-Cost Housing Schemes. International Journal of Physical and Human Geography. 1(3), 1-8

13. United Nations/Habitat (1984). Promotion of Non-conventional Approaches to Housing Finance for low-income groups. Nairobi: United Nation Centre for Human Settlements. 